\title{
ARTICLE
}

\section{Calcium-Doped Boron Nitride Aerogel Enables Infrared Stealth at High Temperature Up to $1300{ }^{\circ} \mathrm{C}$}

Cite as

Nano-Micro Lett.

(2022) $14: 18$

\author{
Mengya Zhu ${ }^{1,2}$, Guangyong Li $^{2}$, Wenbin Gong ${ }^{3}$, Lifeng Yan $^{4}$, Xuetong Zhang ${ }^{2,5} \bowtie$
}

Received: 24 August 2021

Accepted: 22 October 2021

Published online: 6 December 2021

(C) The Author(s) 2021

\section{HIGHLIGHTS}

- A calcium-doped boron nitride (Ca-BN) aerogel was synthesized by introducing Ca into crystal structure of BN building blocks.

- The aerogels exhibited superior high-temperature stability and could resist the burning of butane flame $\left(\sim 1300{ }^{\circ} \mathrm{C}\right)$ in air atmosphere.

- Ca-BN aerogel, together with $\mathrm{Al}$ foil, can effectively hide thermal target at high temperature up to $1300^{\circ} \mathrm{C}$.

\begin{abstract}
Boron nitride (BN) aerogels, composed of nanoscale BN building units together with plenty of air in between these nanoscale building units, are ultralight ceramic materials with excellent thermal/ electrical insulation, great chemical stability and high-temperature oxidation resistance, which offer considerable advantages for various applications under extreme conditions. However, previous $\mathrm{BN}$ aerogels cannot resist high temperature above $900{ }^{\circ} \mathrm{C}$ in air atmosphere, and hightemperature oxidation resistance enhancement for $\mathrm{BN}$ aerogels is still a great challenge. Herein, a calcium-doped $\mathrm{BN}(\mathrm{Ca}-\mathrm{BN})$ aerogel with enhanced high-temperature stability (up to $\sim 1300{ }^{\circ} \mathrm{C}$ in air) was synthesized by introducing $\mathrm{Ca}$ atoms into crystal structure of $\mathrm{BN}$ building

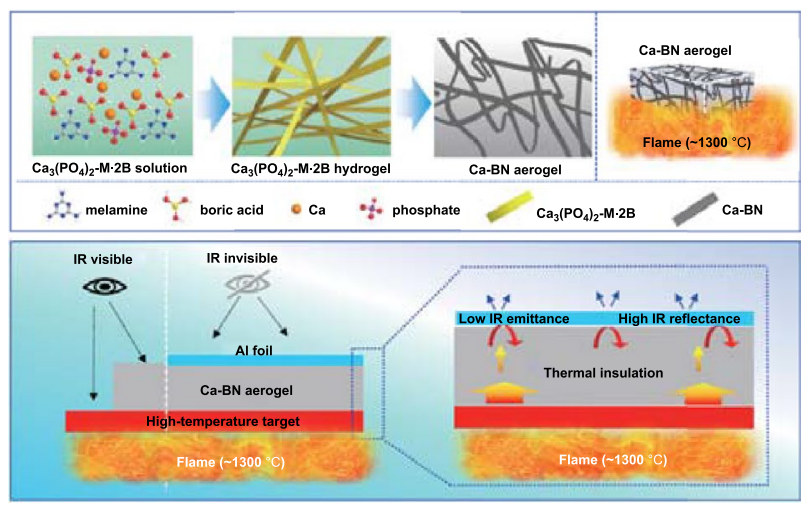
blocks via high-temperature reaction between calcium phosphate and melamine diborate architecture. Such Ca-BN aerogels could resist the burning of butane flame $\left(\sim 1300^{\circ} \mathrm{C}\right)$ and keep their megashape and microstructure very well. Furthermore, Ca-BN aerogel serves as thermal insulation layer, together with $\mathrm{Al}$ foil serving as both low-infrared-emission layer and high-infrared-reflection layer, forming a combination structure that can effectively hide high-temperature target (heated by butane flame). Such successful chemical doping of metal element into crystal structure of BN may be helpful in the future design and fabrication of advanced BN aerogel materials, and further extending their possible applications to extremely high-temperature environments.
\end{abstract}

KEYWORDS Aerogel; Boron nitride; Calcium doping; Infrared stealthy; Butane flame

\footnotetext{
Mengya Zhu and Guangyong Li contributed equally to this work.

$\bowtie$ Xuetong Zhang, xtzhang2013@ sinano.ac.cn; xuetong.zhang@ucl.ac.uk

1 School of Nano-Tech and Nano-Bionics, University of Science and Technology of China, Hefei 230026, People's Republic of China

2 Suzhou Institute of Nano-Tech and Nano-Bionics, Chinese Academy of Sciences, Suzhou 215123, People's Republic of China

3 School of Physics and Energy, Xuzhou University of Technology, Xuzhou 221018, People's Republic of China

4 School of Chemistry and Materials Science, University of Science and Technology of China, Hefei 230026, People's Republic of China

5 Division of Surgery \& Interventional Science, University College London, London NW3 2PF, UK
} 


\section{Introduction}

Boron nitride $(\mathrm{BN})$ aerogels are the ultralight ceramic materials assembled by $\mathrm{BN}$ nanoscale building block [1-3], and they exhibit low density, large specific surface area, excellent thermal/electrical insulation, outstanding chemical stability and desirable high-temperature oxidation resistance, which offer considerable advantages for various applications under extreme conditions [3], such as high-temperature superinsulation, thermal protection and environmental cleaning in harsh environment (acid, alkali), while the polymeric and carbonaceous aerogels could collapse easily with performance damping [4-7]. During the process of BN aerogels, how to construct porous network with nanoscale skeleton using BN nanoscale building blocks is of great significance for the mainstay of various applications [1]. Unfortunately, most of pristine $\mathrm{BN}$ nanoscale building blocks were fabricated by CVD growth or exfoliation from bulky BN, and they involve hazardous chemicals and arduous procedures $[8,9]$. Moreover, the pristine $\mathrm{BN}$ nanoscale building blocks exhibited instinct chemical inertness and poor solution chemistry $[8,10,11]$, so the traditional molecular sol-gel process that utilizes hydrolysis-condensation of small precursor solution cannot fit in well with the BN aerogel [12, 13], which further limit BN aerogels to very few varieties and hinder their practical applications.

To add the diversity of $\mathrm{BN}$ aerogel microstructures and unlock their applications, various specific synthetic strategies that are different to the traditional sol-gel process have been explored [1-3], and various building blocks with different dimension were successfully used to construct $\mathrm{BN}$ aerogel porous network, such as nanoribbon [14, 15], nanotube [16], nanosheet [17] and micro-/nanofiber [18]. Briefly, Rousseas et al. developed a BN aerogel with highly chemical purity via the carbothermal reduction reaction between graphene aerogel, boron oxide and nitrogen, and this aerogel exhibited a unique interlinking structure [2]. Xu et al. designed a BN aerogel with the hyperbolic architecture through a graphene aerogel-assisted chemical vapor deposition process, and this BN aerogel exhibited double-negativeindex (negative Poisson's ratio and negative linear thermal expansion coefficient), which could serve as an ideal insulator for thermal superinsulation under extreme conditions [3]. However, most of the previous BN aerogels still cannot resist high temperature above $900{ }^{\circ} \mathrm{C}$ in air atmosphere, and the intrinsic chemical inertness of BN makes it impossible to enhance the high-temperature stability via chemical doping or modifying in solution. Therefore, the design and synthesis of advanced BN aerogels which can be applied at high temperature above $900{ }^{\circ} \mathrm{C}$ in the air are still a great challenge.

Herein, a calcium-doped boron nitride (Ca-BN) aerogel with enhanced high-temperature stability was fabricated through high-temperature treatment of calcium phosphatedoped melamine diborate architecture. The aerogel was constructed by intertwined Ca-BN micro-/nanoribbons, and $\mathrm{Ca}$ atoms were successfully doped into the crystal structure of $\mathrm{BN}$ nanoscale building blocks. Benefited from the doping of $\mathrm{Ca}$ atoms, the resultant $\mathrm{Ca}-\mathrm{BN}$ aerogel exhibited superior hightemperature stability $\left(\sim 400{ }^{\circ} \mathrm{C}\right.$ higher than pure $\mathrm{BN}$ aerogel). To be specific, the $\mathrm{Ca}-\mathrm{BN}$ aerogel could resist burning of butane flame (up to $1300{ }^{\circ} \mathrm{C}$ ) and maintain the microstructure very well. Moreover, $\mathrm{Ca}-\mathrm{BN}$ aerogel together with $\mathrm{Al}$ foil, forming a combined structure which can effectively hide hightemperature target (heated by butane flame). The successful chemical doping with metal element into crystal structure of BN may be helpful in the future design and fabrication of advanced BN nanostructures and relevant aerogel materials, and further extend their application in extreme conditions.

\section{Experimental Section}

\subsection{Materials and Methods}

\subsubsection{Materials}

Calcium chloride dihydrate $\left(\mathrm{CaCl}_{2} \cdot 2 \mathrm{H}_{2} \mathrm{O}\right.$, powder, $\left.99.0 \%\right)$, phosphoric acid $\left(\mathrm{H}_{3} \mathrm{PO}_{4}, 99.0 \%\right.$, powder $)$, boric acid $\left(\mathrm{H}_{3} \mathrm{BO}_{3}, \mathrm{AR}, 99.5 \%\right)$, melamine $\left(\mathrm{C}_{3} \mathrm{~N}_{6} \mathrm{H}_{6}, \mathrm{AR}, 99.0 \%\right)$, triethylamine $\left(\left(\mathrm{C}_{2} \mathrm{H}_{5}\right)_{3} \mathrm{~N}, 99.0 \%\right)$, ethanol $\left(\mathrm{C}_{2} \mathrm{H}_{5} \mathrm{OH}, 99.7 \%\right)$ and tertiary butyl alcohol $\left(\mathrm{C}_{4} \mathrm{H}_{10} \mathrm{O}, 99.7 \%\right)$ were purchased from Aladdin Company. Argon gas was purchased from Linde Group, Suzhou.

\subsubsection{Synthesis of $\mathrm{Ca}_{3}\left(\mathrm{PO}_{4}\right)_{2}$ Ionic Oligomer}

$\mathrm{Ca}_{3}\left(\mathrm{PO}_{4}\right)_{2}$ ionic oligomer was prepared according to the method of the literature [19]: typically, dissolving $0.588 \mathrm{~g}$ calcium chloride dihydrate in $48 \mathrm{~mL}$ ethanol, dissolving $0.262 \mathrm{~g}$ phosphoric acid and adding a certain amount of 
triethylamine (molar ratio $\mathrm{Ca}: \mathrm{TEA}=1: 20$ ) in $32 \mathrm{~mL}$ ethanol. The subsequent quick mixing of these two solutions by stirring generates a transparent or semitransparent solution that contained $\mathrm{Ca}_{3}\left(\mathrm{PO}_{4}\right)_{2}$ ionic oligomers within $30 \mathrm{~min}$. $\mathrm{Ca}_{3}\left(\mathrm{PO}_{4}\right)_{2}$ ionic oligomers were concentrated by the highspeed centrifugation and then redispersed in tertiary butyl alcohol (TBA) twice to remove impurities and then obtained the $\mathrm{Ca}_{3}\left(\mathrm{PO}_{4}\right)_{2}$ ionic oligomers solution.

\subsubsection{Synthesis of Calcium-Doped Boron Nitride Aerogel}

Dissolve $0.989 \mathrm{~g}$ boric acid and $1.137 \mathrm{~g}$ melamine in $44 \mathrm{~mL}$ $\mathrm{H}_{2} \mathrm{O}$ and $38 \mathrm{~mL}$ TBA co-solvent system at $85 \sim 90{ }^{\circ} \mathrm{C}$ water bath under stirring within $30 \mathrm{~min}$ to obtain a transparent solution. Add the $\mathrm{Ca}_{3}\left(\mathrm{PO}_{4}\right)_{2}$ ionic oligomers solution obtained in the previous step into the hot solution, and stir for a few minutes to get another mixing transparent solution $\left(\mathrm{Ca}_{3}\left(\mathrm{PO}_{4}\right)_{2}-\mathrm{M} \cdot 2 \mathrm{~B}\right.$ solution). The hot mixing solution was cooled naturally under simultaneously ultrasonic treatment until get a white hydrogel precursor $\left(\mathrm{Ca}_{3}\left(\mathrm{PO}_{4}\right)_{2}-\mathrm{M} \cdot 2 \mathrm{~B}\right.$ hydrogel). Subsequently, the hydrogel was freeze-dried to get a white aerogel-like precursor $\left(\mathrm{Ca}_{3}\left(\mathrm{PO}_{4}\right)_{2}-\mathrm{M} \cdot 2 \mathrm{~B}\right.$ aerogel). Finally, the precursor was transferred to a horizontal quartz tube and heated to $1400{ }^{\circ} \mathrm{C}$ for $3 \mathrm{~h}$ in the presence of argon gas, and a white calcium-doped boron nitride aerogel (Ca-BN aerogel) was obtained.

\subsection{Characterization}

The morphology of the samples was characterized by field emission scanning electron microscope (SEM) (S-4800, Hitachi Company, Japan) operated at 10-20 kV, and $\mathrm{Ca}-\mathrm{BN}$ aerogel was coated with Au sputtering under current of $25 \mathrm{~mA}$ for $2 \mathrm{~min}$. Field emission transmission electron microscope (TEM) was carried out on Tecnai G2 F20 STWIN (FEI Company, USA) with the acceleration voltage of $200 \mathrm{kV}$. STEM and element mapping were collected by spherical aberration-corrected TEM (FEI Themis Z). The pore structure of the aerogels was investigated using a surface area analyzer (ASAP 2020 HD88, Micrometrics, Inc., USA). The Brunauer-Emmett-Teller (BET) method and the Barrett-Joyner-Halenda (BJH) model were utilized to calculate the BET specific surface area (SSA) and the pore size distribution.
The crystal structure of the as-prepared samples was investigated by X-ray diffraction (XRD, D8 advance, Bruker AXS). Raman spectroscopic investigation was carried out by laser confocal Raman spectrometer (LABRAM HR, Horriba-JY). The XPS spectra were measured by Escalab 250Xi, Thermo Scientific. Thermal stealthy and relevant IR images were recorded by Escalab $250 \mathrm{Xi}$, Thermo Scientific. The room temeprature thermal conductivity of samples was measured by transient hot wire method (XIATECH TC3000, China), and the data were collected five times with a 5-min interval between each measurement. TG and high-temperature thermal conductivity were measured via BioEngX. TG was carried out using NETZSCH STA 449F3. High-temperature thermal conductivity was carried out using Hot disk (base on international standard ISO 22007-2). Temperature detection was carried by IR thermometer (ISR 6 Advanced, LumaSense IMPAC).

\subsection{Simulation}

Simulations combined molecular dynamics (MD) and density functional theory (DFT) were performed to investigate the structures of the $\mathrm{Ca}_{3}\left(\mathrm{PO}_{4}\right)_{2}-\mathrm{M} \cdot 2 \mathrm{~B}$ precursor and $\mathrm{Ca}-\mathrm{BN}$ samples. The $\mathrm{MD}$ calculations were performed in the canonical ensemble at $300 \mathrm{~K}$ by using LAMMPS (large-scale atomic/ molecular massively parallel simulator) code. The DREIDING forcefield was employed to describe the inter- and intra-interactions of $\mathrm{Ca}_{3}\left(\mathrm{PO}_{4}\right)_{2}$ and $\mathrm{M} \cdot 2 \mathrm{~B}$ molecules, while the atomic charges were calculated with the charge equilibration (QEq) method. The DREIDING forcefield was chosen because its validity in simulating the M-2B-related systems had been checked before. The structures of Ca-BN were investigated by performing the plane-wave-based DFT method implemented in the VASP (Vienna Ab Initio Simulation Package) code. A $6 \times 6 \times 1$ bilayer h-BN with a $20 \AA$ vacuum region, whose Brillouin zone was sampled by a $3 \times 3 \times 1 \mathrm{k}-\mathrm{mesh}$, was constructed for all the simulations. A $\mathrm{Ca}$ atom was introduced into the model by either intercalating into the h-BN or substituting the $\mathrm{B}$ or $\mathrm{N}$ atoms of the h-BN. The electron ion interaction was described with the projector augmented wave method with the Perdew-Burke-Ernzerhof potential for the exchange-correlation functional. The cutoff energy was set to be $400 \mathrm{eV}$. The long-range van der Waals interactions were calculated with the Tkatchenko and Scheffler scheme, while the self-consistent screening and 

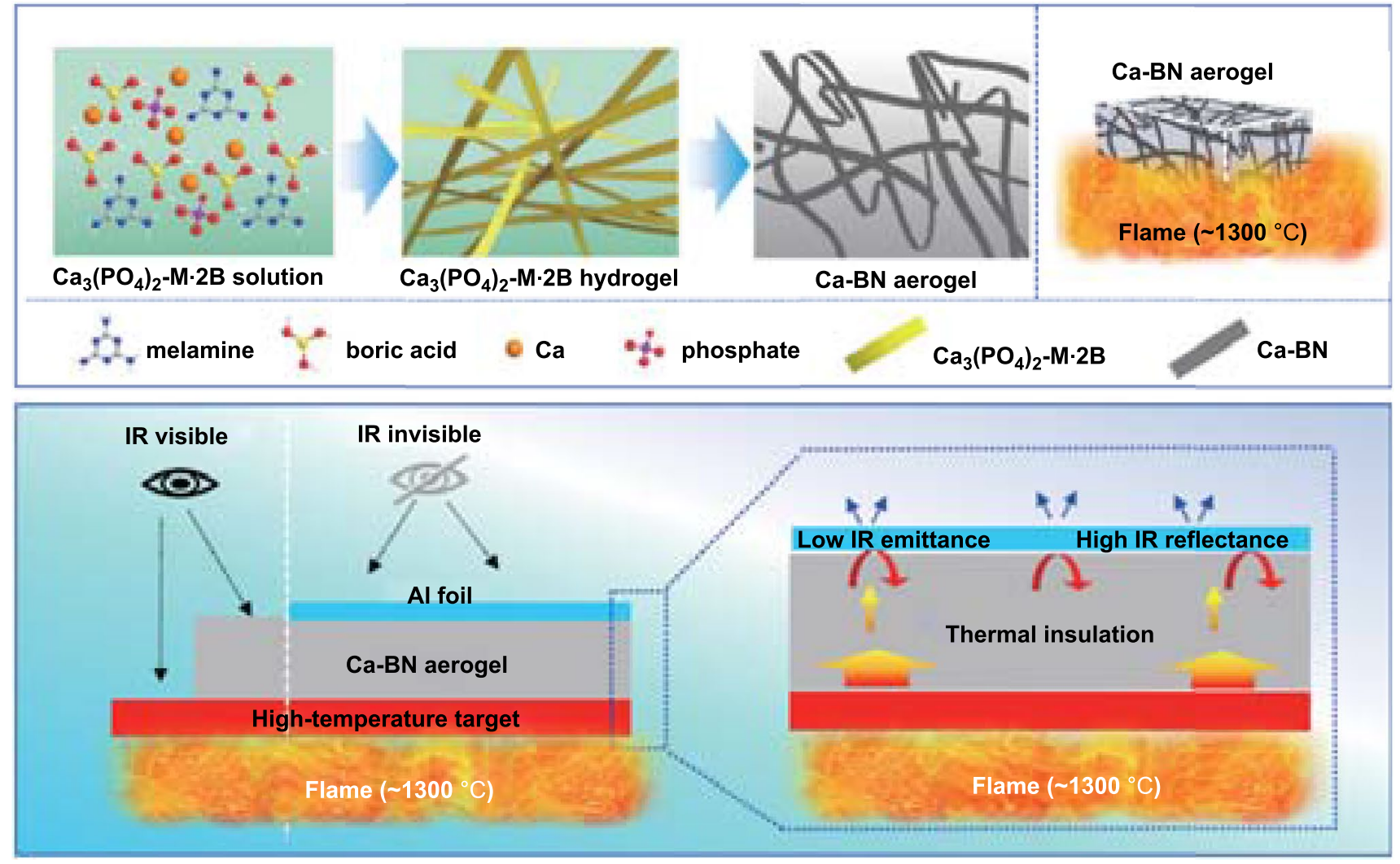

Scheme 1 a Schematic synthesis of Ca-BN aerogels. b Scheme of high-temperature stabilization of Ca-BN aerogel. c Scheme of high-temperature infrared stealthy of $\mathrm{Ca}-\mathrm{BN}$ aerogel together with $\mathrm{Al}$ foil at high temperature up to $1300{ }^{\circ} \mathrm{C}$

polarizability contraction effects were also considered, in view of their important roles in determining the weak intermolecular interactions of h-BN. The geometry optimization was performed when the convergence criterion on forces became smaller than $0.02 \mathrm{eV}^{-1}$ and the energy difference was set to be $10^{-5} \mathrm{eV}$.

\section{Results and Discussion}

\subsection{Characterization of Ca-BN Aerogel}

For the pure BN, it is easy to oxidize into boric oxide and then evaporate rapidly in high-temperature (above $900{ }^{\circ} \mathrm{C}$ ) oxidative environment $[3,14]$. To improve the high-temperature oxidation resistance of $\mathrm{BN}$ aerogel material, it is essential to reduce the evaporation of boric oxide, and then form a fixed molten film structure on the surface of BN nanoscale building blocks. It has been known that the metallic oxide can react with melted boric oxide and generate an infusible or involatile compound (e.g., $\mathrm{xCaO} \cdot \mathrm{yB}_{2} \mathrm{O}_{3}$ system) during glass process [20-22]. Inspired by the production process of glass in the industry, the $\mathrm{Ca}$ atoms were introduced into the crystal structure of $\mathrm{BN}$ through the high-temperature treatment of calcium phosphate-doped melamine diborate (M.2B) architecture.

As shown in Scheme 1a and Fig. S1, the melamine, boron acid and calcium phosphate oligomer [19] were added into the hot water/tertiary butanol (TBA) co-solvent in sequence, and they formed a transparent and uniform mixed solution, and then, the solution is cooled to ca. $30^{\circ} \mathrm{C}$ under the assistance of ultra-sonication to obtain a white hydrogel; after freezing-drying and high-temperature treatment $\left(1400{ }^{\circ} \mathrm{C}, \mathrm{Ar}\right.$ atmosphere), the final Ca-BN aerogel with low density $\left(20.41 \mathrm{mg} \mathrm{cm}^{-3}\right)$ and white appearance was obtained (Fig. 1a). The melamine and boric acid have long been recognized as cheap and common precursors for BN [1], and they could assemble into melamine diborate $(\mathrm{M} \cdot 2 \mathrm{~B})$ nanoscale building block via the hydrogen bonding in the water/TBA co-solvent [14], while calcium 

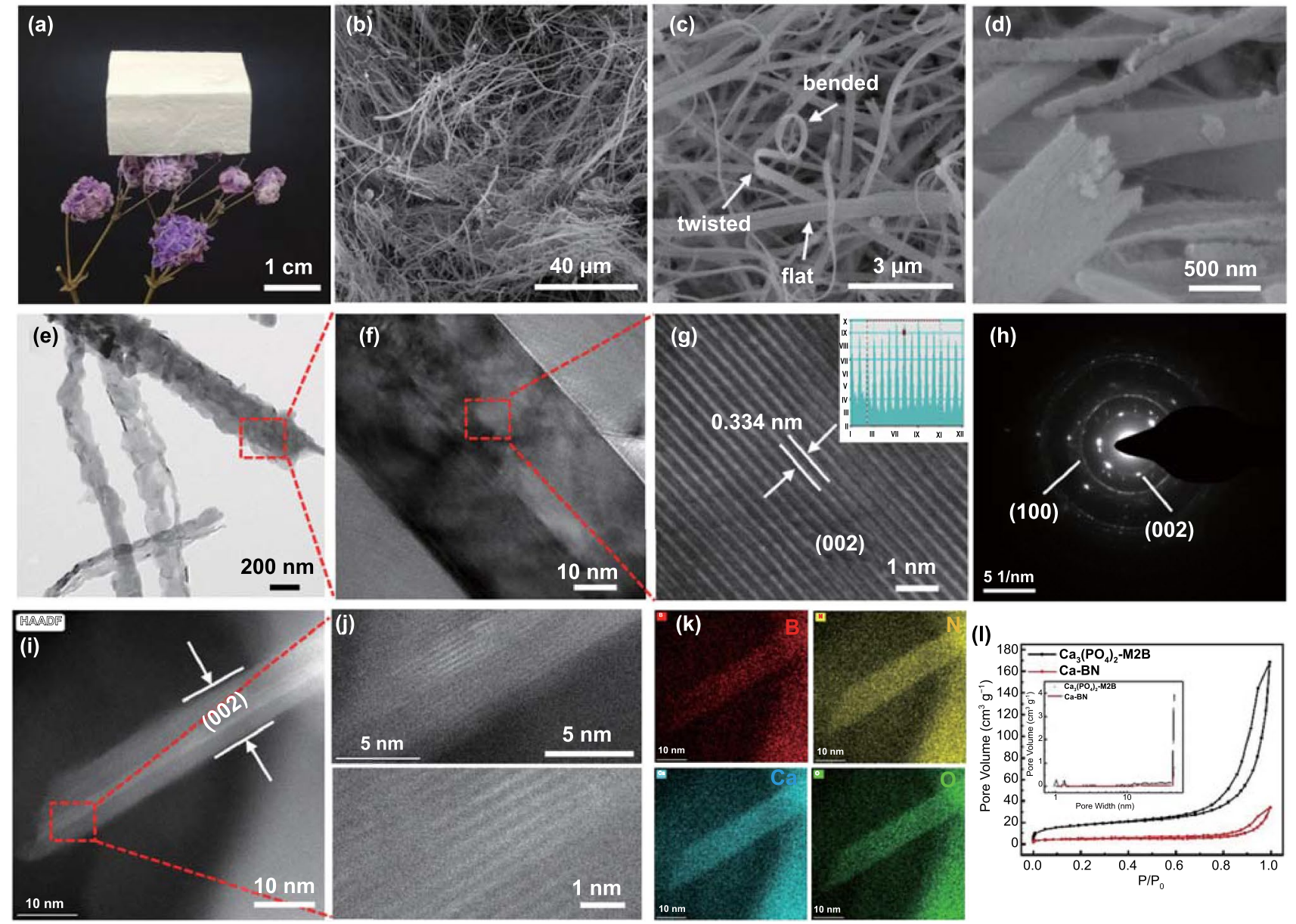

Fig. 1 a Optical image of Ca-BN aerogel. b-d SEM images of Ca-BN aerogel. e-f TEM images of Ca-BN aerogel. $\mathbf{g}-\mathbf{h}$ HRTEM image and the corresponding electron diffraction pattern of Ca-BN aerogel. $\mathbf{i}-\mathbf{j}$ STEM images of Ca-BN aerogel. $\mathbf{k}$ STEM-EDS mappings of Ca-BN aerogel. $\mathbf{l}$ Nitrogen adsorption-desorption isotherm curves of Ca-BN aerogel and Calcium phosphate-doped M-2B precursor. Inset in image $\mathbf{l}$, the corresponding pore size distribution curves

phosphate could link to amine group (e.g., triethylamine, ethanediamine, melamine molecules) via hydrogen bonding and this has been reported elsewhere [19]. According to hydrogen bonding interaction, calcium phosphate will embed into the crystal structure of M.2B, which provides opportunity to dope $\mathrm{Ca}$ atoms into crystal structure of $\mathrm{BN}$ nanoscale building blocks, and results in a $\mathrm{Ca}-\mathrm{BN}$ aerogel with enhanced high-temperature stability (Scheme 1b). Furthermore, $\mathrm{Ca}-\mathrm{BN}$ aerogel serves as thermal insulation layer, together with $\mathrm{Al}$ foil serving as both low-infrared-emission layer and high-infrared-reflection layer, forming a combination structure that can effectively hide high-temperature target (Scheme 1c).

The morphology of Ca-BN aerogel was investigated by SEM. As shown in Fig. 1b-d, large amounts of micro-/ nanoribbons intertwined and interweaved with each other to form a porous network, and cross sections of micro-/nanoribbons exhibit whisker-like structure with the irregular end and rough surface, resembling to the calcium phosphatedoped M-2B precursor (Fig. S2). The porous structure was further quantified by nitrogen sorption (Fig. 11), and the isotherm curve of $\mathrm{Ca}-\mathrm{BN}$ aerogel possessed a rapid increase in the low-pressure range $\left(\mathrm{P} / \mathrm{P}_{0}<0.02\right)$ and a hysteresis loop, which implied the existence of micropores and meso-pores in Ca-BN aerogel. According to Barrett-Joyner-Halenda $(\mathrm{BJH})$ analyses, the specific surface area was about 14.7 $\mathrm{m}^{2} \mathrm{~g}^{-1}$.

Furthermore, the microstructure of single Ca-BN micro-/ nanoribbon was recorded by TEM images (Figs. 1e, g and S3, S4). It is interesting to note that micro-/nanoribbons 
consist of many stripe-like and overlapped nanocrystals, most of these nanocrystals were distributed throughout micro-/nanoribbon and some of them are dendritic crystals hang on the edge of micro-/nanoribbon; as shown in Figs. If and S3, S4, the size of single nanocrystal could reach to hundreds of nanometers (Fig. 1f, g), which is different from the amorphous structure in previous BN nanoribbon aerogel without chemical doping (Fig. S5) [14]. Moreover, the clear lattice fringes were observed in the high-resolution TEM image and they displayed a typical layer spacing of $\sim 0.334 \mathrm{~nm}$ (Fig. 1f, g), which is consist with that of bulk h-BN (0.333 nm, Fig. S6); such results were further confirmed by the selected area electron diffraction patterns (Figs. 1h and S4) [18, 23], XRD (Figs. 2a and S6, S7) and Raman (Fig. 2b) spectra. Typically, Ca-BN aerogel exhibited high crystalline similar to pristine h-BN, while BN aerogel derived from M-2B monolith was amorphous (Fig. S6).

To investigate and confirm the existence of $\mathrm{Ca}$ in aerogel, the element mappings of single nanocrystal (crystal plane, 002) with clear lattice fringes (Figs. 1i, j and S8, S9) were recorded firstly. $\mathrm{B}, \mathrm{N}, \mathrm{O}$ and $\mathrm{Ca}$ elements are uniformly distributed along and across the single nanocrystal (Fig. 1k),
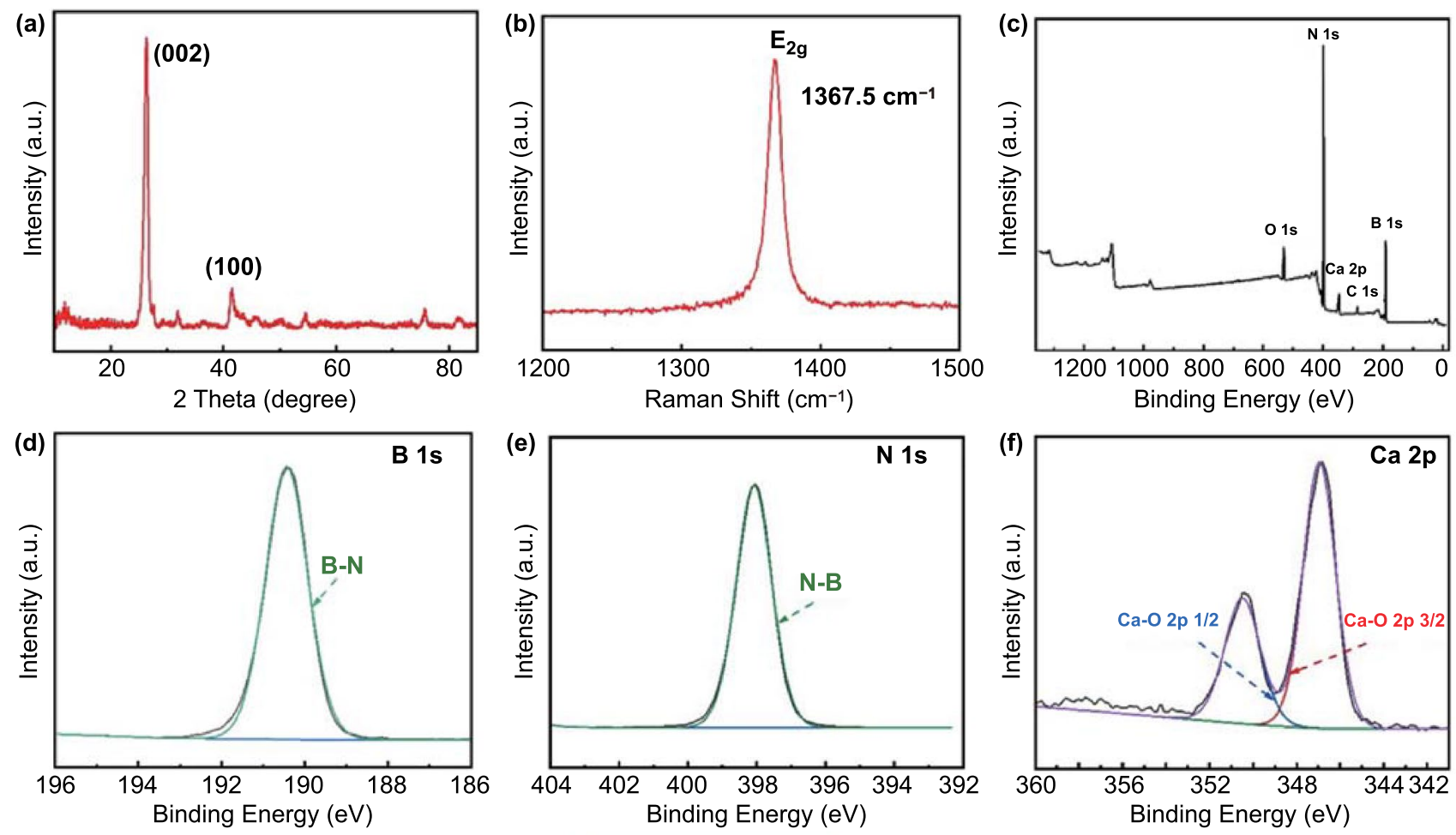

(g)
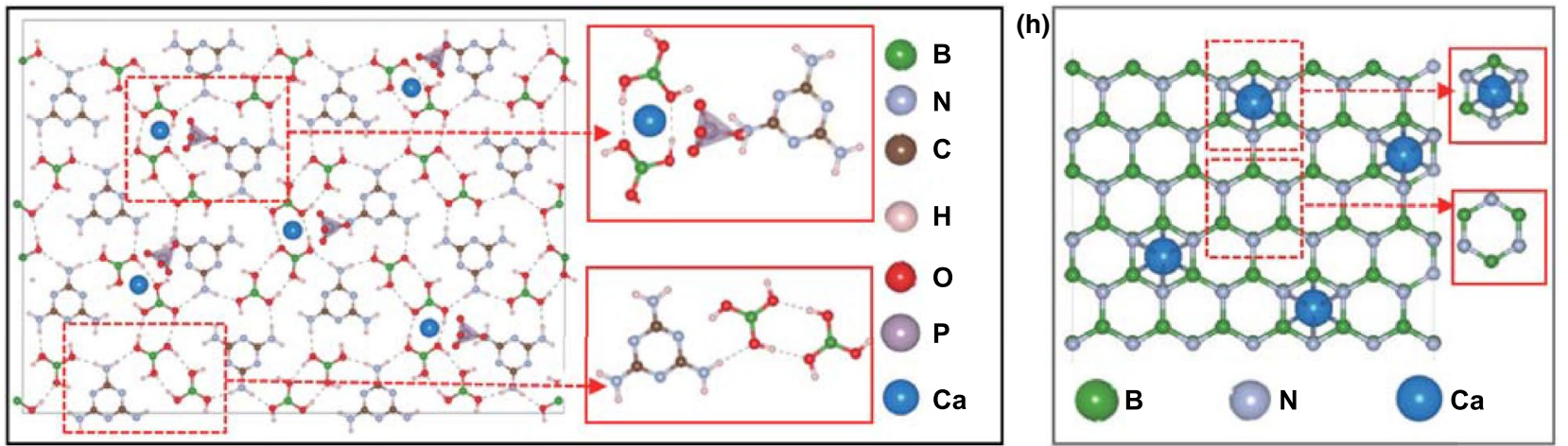

Fig. 2 a XRD pattern of Ca-BN aerogel. b Raman spectrum of Ca-BN aerogel. c XPS survey of Ca-BN aerogel. d-f B 1s, N 1s, Ca 2p spectra of Ca-BN aerogel. $\mathbf{g}$ Schematic plots of $\mathrm{Ca}_{3}\left(\mathrm{PO}_{4}\right)_{2}$ molecule adsorbed on $\mathrm{M} \cdot 2 \mathrm{~B}$. $\mathbf{h}$ Schematic plots of $\mathrm{Ca}$ atom in Ca-BN, the insets illustrate the detailed structure 
but phosphorous (P) element cannot be detected (Fig. S9). It is speculated that in the process of high-temperature annealing, the calcium phosphate occurred carbothermal reduction reaction with carbon and boric oxide, and then, phosphorus volatilized in the form of phosphorus oxide. Notably, as element signals were collected on the lattice fringe of typical (002) crystal face of BN, no other crystal or amorphous structures were observed, and $\mathrm{Ca}$ element distributed in this crystal plane, indicating $\mathrm{Ca}$ element was dopped into the crystal structure of BN.

The chemical compositions were further confirmed by X-ray photoelectron spectroscopy (XPS) spectra (Figs. 2c, f and $\mathrm{S} 10-\mathrm{S} 12$ ), the $\mathrm{B}, \mathrm{N}, \mathrm{C}, \mathrm{O}$ and $\mathrm{Ca}$ elements were detected in the $\mathrm{Ca}-\mathrm{BN}$ aerogel, and $\mathrm{P}$ element still cannot be detected, which consists to the results of the above element mapping (Figs. 1k and S9). Furthermore, both high-resolution XPS B $1 \mathrm{~s}$ and N $1 \mathrm{~s}$ spectra can be fitted into one peak at 190.4 (Fig. 2d) and 398.1 (Fig. 2e) eV, respectively, which confirms the formation of BN. For Ca $2 p$ spectrum (Fig. 2f), and there are two fitted peaks located at 346.9 and $350.4 \mathrm{eV}$, corresponding to $2 \mathrm{p}_{3 / 2}$ and $2 \mathrm{p}_{1 / 2}$ (generated by the spin-orbit splitting), respectively, which can be assigned to $\mathrm{Ca}-\mathrm{O}$. O $1 \mathrm{~s}$ spectrum also shows the $\mathrm{Ca}-\mathrm{O}$ bond at $531.5 \mathrm{eV}$ (Fig. $\mathrm{S} 12)$, indicating $\mathrm{Ca}$ element existed as $\mathrm{Ca}-\mathrm{O}$ compound in Ca-BN aerogel (Figs. S10-S12).

To investigate the role of calcium phosphate oligomer in fabrication process of $\mathrm{Ca}-\mathrm{BN}$ aerogel, calcium phosphate oligomer solution was freeze-dried firstly, and the obtained solid consisted of large amounts of irregular particles and pieces (Fig. S13). However, such irregular or flaky morphologies were not found in calcium phosphate-doped M-2B precursor (Fig. S2). If calcium phosphate oligomer was replaced by commercial calcium phosphate powder and used to fabricate calcium phosphate/M-2B composite precursor, the obtained precursor monolith exhibited lots of micron-sized particles in the porous network constructed by ribbons (Figs. S14 and S15). These different morphologies of the above samples provided preliminary evidence that the calcium phosphate oligomer is essential to this fabrication and it was embedded into M-2B ribbon. Moreover, as calcium phosphate oligomer was introduced into $\mathrm{M} \cdot 2 \mathrm{~B}$ units, the obtained ribbons exhibited a typical whisker-like structure in their cross section (Figs. 1d and S16), indicating that these ribbons were consisted of large amounts of banded ligatures, which is different from the nanoribbons of pure $\mathrm{M} \cdot 2 \mathrm{~B}$ nanoribbon (smooth hexagonal end) in previous reports $[1,14]$.

To understand the existing form of $\mathrm{Ca}$ element in aerogel, simulations combined molecular dynamics (MD) and density functional theory (DFT) were performed. It is found that the $\mathrm{Ca}_{3}\left(\mathrm{PO}_{4}\right)_{2}$ molecule is adsorbed on the $\mathrm{M} \cdot 2 \mathrm{~B}$ precursor through electrostatic and $\mathrm{H}$ bonding interaction as shown in Fig. 2g, without destroying the M-2B network. As a result, $\mathrm{Ca}_{3}\left(\mathrm{PO}_{4}\right)_{2}$ molecule could serve as an excellent binder to connect the adjacent M.2B sheets in the solvent. With the high-temperature treatment, the Ca-BN sample was obtained. The $\mathrm{Ca}$ atom will either substitute a $\mathrm{B} / \mathrm{N}$ atom in a single layer or exist in the space between the adjacent $\mathrm{Ca}-\mathrm{BN}$ sheets. DFT simulations indicate that the $\mathrm{Ca}$ substitution of $\mathrm{B}$ or $\mathrm{N}$ atom leads to a narrowed interlayer distance (d) about 3.14 Angstrom compared with raw $\mathrm{Ca}-\mathrm{BN}$ with the $\mathrm{d}$ about 3.31 Angstrom, with the intercalation of $\mathrm{Ca}$ atom in $\mathrm{Ca}-\mathrm{BN}$ results in a slightly expanded d about 3.36 Angstrom. Since the observed interlayer distance $d$ in the experiment is about 3.4 Angstrom, the $\mathrm{Ca}$ atom should be existed in h-BN with the intercalation form as shown in Fig. $2 \mathrm{~h}$.

Mechanical property of Ca-BN aerogel was investigated by compress test (Fig. S17). The stress-strain curve exhibited three deformation regimes: an initial Hookean region (elastic deformation) at strain $\varepsilon<8 \%$ with a Young's modulus of about $25 \mathrm{kPa}$, a plateau (plastic deformation) and the final densification region. In addition, as $\mathrm{Ca}-\mathrm{BN}$ aerogel was compressed to different strains, respectively, $\varepsilon$ from 5 to $25 \%$ with an interval of 5\%, it can recover to original shape (Fig. $\mathrm{S} 17 \mathrm{~b}$ ), indicating $\mathrm{Ca}-\mathrm{BN}$ aerogel was mechanical elasticity.

\subsection{High-Temperature Stability of Ca-BN Aerogel}

To investigate the high-temperature oxidation resistance performance of $\mathrm{Ca}-\mathrm{BN}$ aerogel, a butane flame $\left(\sim 1300{ }^{\circ} \mathrm{C}\right)$ was used to burn $\mathrm{Ca}-\mathrm{BN}$ aerogel for about $6 \mathrm{~min}$, and the megashape of the white aerogel monolith maintained very well (Fig. 3a), while the pure BN aerogel monolith faded away and disappeared nearly invisible (Fig. 3b). Moreover, temperature of the burned surface of $\mathrm{Ca}-\mathrm{BN}$ aerogel was detected by infrared thermometer, and it could reach to about $\sim 1309{ }^{\circ} \mathrm{C}$ (Figs. $4 \mathrm{~b}$ and S18), which provided a direct evidence to confirm the temperature could be up to $1300{ }^{\circ} \mathrm{C}$. These different experiment phenomena between 

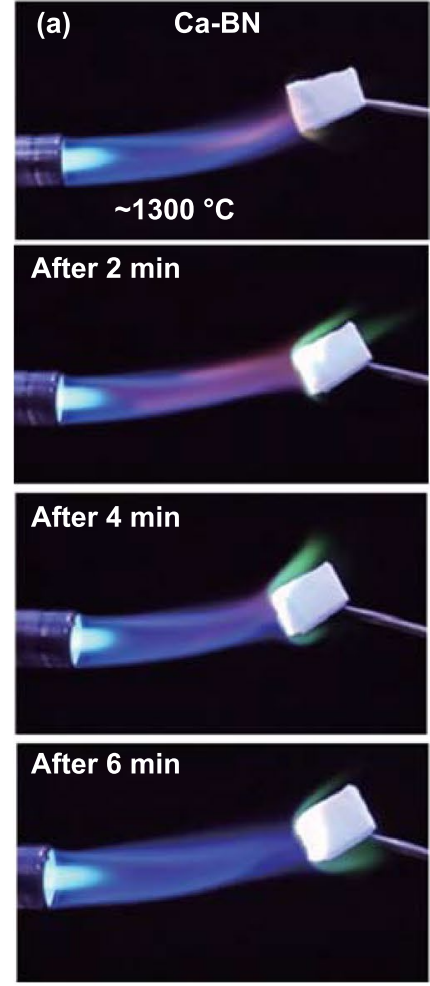
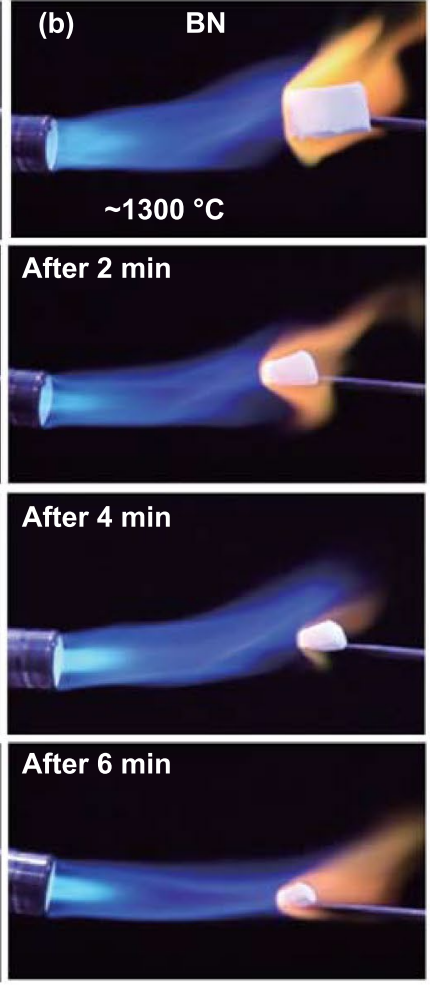
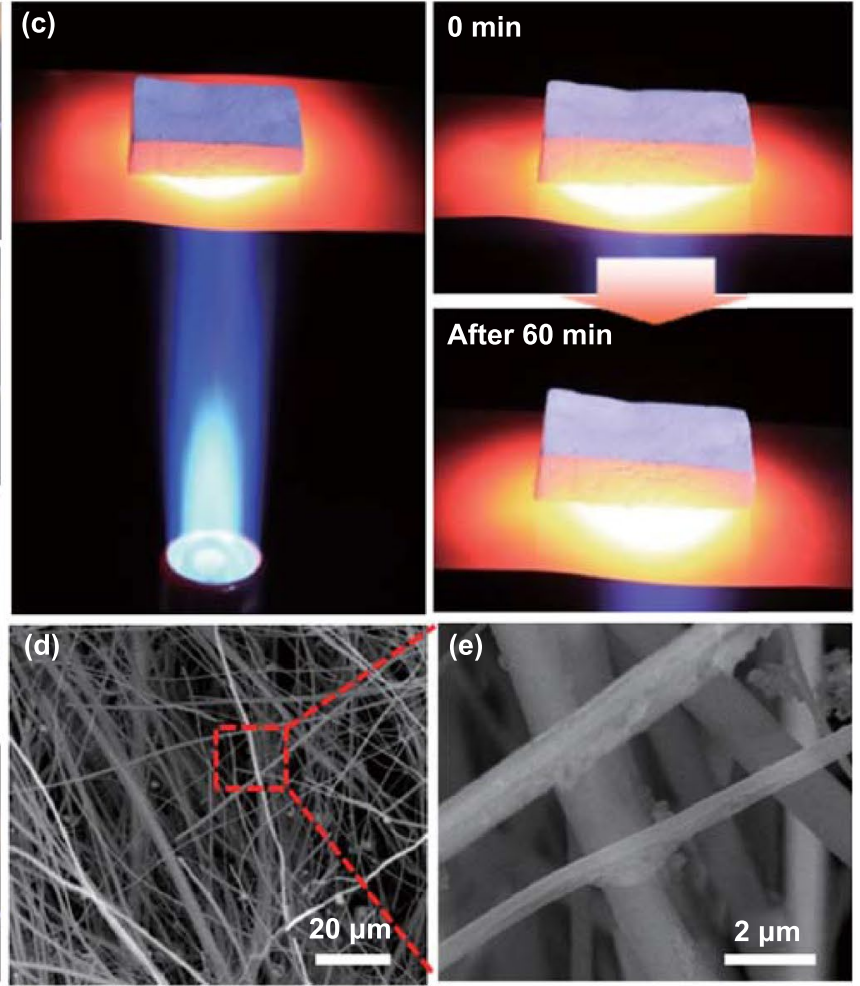

Fig. 3 a-b Optical images of Ca-BN aerogel and pure BN aerogel heated by butane blowtorch flame. c Ca-BN aerogel monolith was placed on the red-hot steel foil which heated by butane flame in air for $1 \mathrm{~h}$. d-e SEM images of bottom surface after heated for 60 min

Ca-BN and pure $\mathrm{BN}$ aerogel mainly attributed to their different chemical composition. Under the burning of butane flame, pure $\mathrm{BN}$ aerogel was oxidized into $\mathrm{B}_{2} \mathrm{O}_{3}$ and then evaporated rapidly (Fig. S19). For the Ca-BN aerogel, the $\mathrm{Ca}$ element could react to melted $\mathrm{B}_{2} \mathrm{O}_{3}$ and then form an involatile melted compound (e.g., $\mathrm{xCaO} \cdot \mathrm{yB}_{2} \mathrm{O}_{3}$ system) [22], and the melted compound covered on the skeleton surface of the aerogel and prevented the further oxidization, as shown in Figs. 3d, e and S19, S20. Moreover, the mixed powder of boric acid and $\mathrm{CaO}$ was heated to about $1300{ }^{\circ} \mathrm{C}$, and the powder becomes transparent solid which adheres on white substrate (Fig. S21), indicating the generation of involatile melted compound. In other words, the above results provided a strong and visual evidence to confirm the effect of $\mathrm{Ca}$ element in $\mathrm{BN}$ aerogels, i.e., $\mathrm{Ca}$ element enhanced the thermal stability and oxidation resistance performances of $\mathrm{BN}$ aerogel.

The high-temperature stabilization of $\mathrm{Ca}-\mathrm{BN}$ aerogel was further investigated according to a unidirectional heating experiment in the air. As the Ca-BN aerogel monolith was placed on the red-hot steel foil which heated by butane flame $\left(\sim 1300{ }^{\circ} \mathrm{C}\right)$, these experiment design could eliminate the shocking of the butane flow generated by flamer (Fig. 3c). After heating for about $60 \mathrm{~min}$, the megashape of aerogel monolith still maintained very well (Fig. 3c). Moreover, during heating process, size and mass of $\mathrm{Ca}-\mathrm{BN}$ aerogel were recorded every $10 \mathrm{~min}$, and the sizes along different directions, color and shape of aerogel monolith are consistent before and after high-temperature treatment (Figs. S20a and S23), while the mass only reduced slightly by less than $1.5 \mathrm{wt} \%$. Under the similar heating condition, the size and mass of pure $\mathrm{BN}$ aerogel exhibited obvious change (Fig. S20b). Furthermore, after heating about $60 \mathrm{~min}$, the bottom (heated) surface morphology was recorded by SEM images, the micro-/nanoribbon building blocks still could be observed, and there was no change in the overall porous network, although there are few hemispherical grains hung on the edge of ribbons (Fig. 3d, e). All these results further indicated that the $\mathrm{Ca}-\mathrm{BN}$ aerogel possessed excellent high-temperature long-term stability in the air, and the $\mathrm{Ca}$ element contributed to such fascinating properties. 

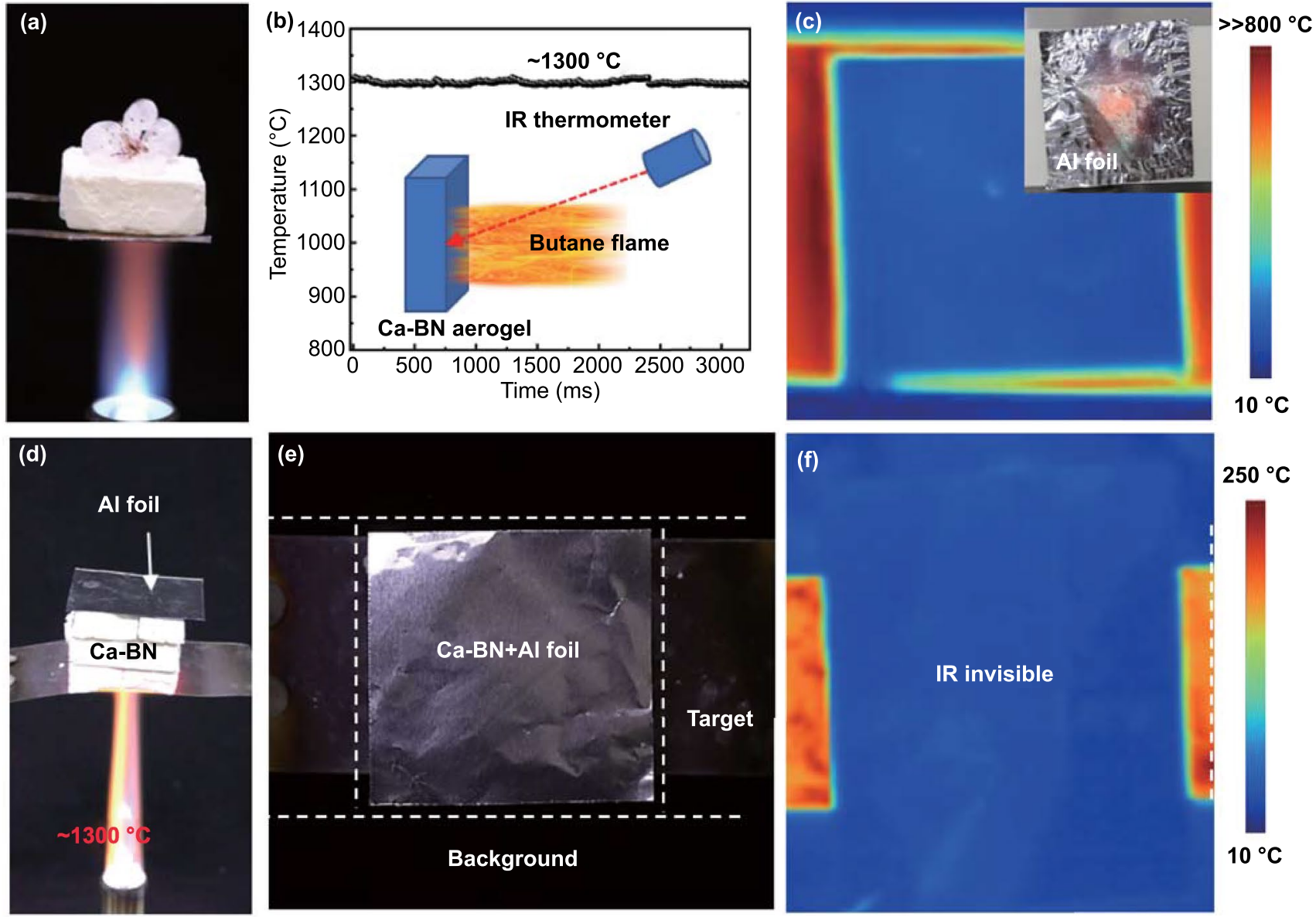

Fig. 4 a Photograph of the high-temperature thermal insulation test of Ca-BN aerogel. Ca-BN aerogel effectively insulates the flower against the fire with temperature up to $\sim 1300{ }^{\circ} \mathrm{C}$. $\mathbf{b}$ Temperature-time curves of Ca-BN aerogel which heated by butane flame. $\mathbf{c}$ IR image of hot target covered by Al foil, and the target was heated by butane flame. d-f Optical images (side view and top view) and IR image of hot target covered by $\mathrm{Ca}-\mathrm{BN}$ aerogel and aluminum foil

\subsection{High-Temperature Thermal Insulation}

In addition to its superior high-temperature oxidation resistance performance, the Ca-BN aerogel still possessed excellent thermal insulation behavior. In general, the thermal conductivity mainly depends on three components: thermal convection, thermal conductivities of gases and solids, and heat radiation. The prepared $\mathrm{Ca}-\mathrm{BN}$ aerogel with plenty of micro-/meso-pores possessed a low density that corresponding to a high pore porosity, which could efficiently mitigate the air conduction and convection. The randomly porous network intertwined by micro-/nanoribbon provided large amount interfaces that can result in a low solid thermal transmission. According to the transient hot wire method at room temperature, the Ca-BN aerogel exhibited a low thermal conductivity of $0.0454 \pm 0.0028 \mathrm{~W} / \mathrm{mK}$, which is comparable to the previous ceramic aerogels and other porous materials, such as $\mathrm{SiO}_{2}-\mathrm{Al}_{2} \mathrm{O}_{3}$ composite sponges (0.034 W mK $\left.{ }^{-1}\right)$ [24], $\mathrm{ZrO}_{2}-\mathrm{Al}_{2} \mathrm{O}_{3}$ nanofibrous aerogels $\left(0.032 \mathrm{~W} \mathrm{mK}^{-1}\right)$ [25] and pure $\mathrm{BN}$ aerogel $(\sim 0.035 \mathrm{~W}$ $\mathrm{mK}^{-1}$ ) derived from $\mathrm{M} \cdot 2 \mathrm{~B}$ precursor [14]. Based on the above comparison, as the Ca element was introduced into $\mathrm{BN}$ aerogel, the thermal conductivity increased slightly, and this mainly attributed to the improved crystal structure of micro-/nanoribbons in the aerogel, which provided an adverse effect for phonon scattering. Moreover, the thermal conductivity of $\mathrm{Ca}-\mathrm{BN}$ aerogel still lower than that of densified $\mathrm{BN}$ aerogel film $\left(0.055 \mathrm{~W} \mathrm{mK}^{-1}\right)$ [15], $\mathrm{BN}$ nanocomposite aerogel $\left(2.2 \mathrm{~W} \mathrm{mK}^{-1}\right)$ [17] and graphene aerogels $\left(0.2-2.1 \mathrm{~W} \mathrm{mK}^{-1}\right)[26,27]$. 
High-temperature thermal conductivities of $\mathrm{Ca}-\mathrm{BN}$ aerogel were further measured by a hot disk thermal analyzer, and their values were about 0.14 and $0.15 \mathrm{~W} \mathrm{mK}^{-1}$ at 900 and $1000{ }^{\circ} \mathrm{C}$, respectively, lower than that of most aerogel materials in the previous reports [28-32], such as $\mathrm{Al}_{2} \mathrm{O}_{3}$ aerogel $\left(0.298 \mathrm{~W} \mathrm{mK}^{-1}\right.$ at $\left.800{ }^{\circ} \mathrm{C}\right)$ [28], core-shell $\mathrm{Al}_{2} \mathrm{O}_{3}$ aerogel/mullite fiber composite $\left(0.16 \mathrm{~W} \mathrm{mK}^{-1}\right.$ at $\left.1000{ }^{\circ} \mathrm{C}\right)$ [29], palygorskite-based aerogels $\left(0.165 \mathrm{~W} \mathrm{mK}^{-1}\right.$ at $\left.1000{ }^{\circ} \mathrm{C}\right)$ [30], aluminum borate foams $\left(0.228 \mathrm{~W} \mathrm{mK}^{-1}\right.$ at $\left.1000{ }^{\circ} \mathrm{C}\right)$ [31] and $\mathrm{BN} / \mathrm{SiOC}$ aerogel $\left(0.215 \mathrm{~W} \mathrm{mK}^{-1}\right.$ at $\left.1000{ }^{\circ} \mathrm{C}\right)$ [32]. Therefore, Ca-BN aerogel exhibits great potential in high-temperature insulation.

Combined with the high-temperature stability and low thermal conductivity, the Ca-BN aerogel could be used as thermal insulator under extreme conditions, such as hightemperature oxidation environment. As shown in Fig. 4a, the Ca-BN aerogel monolith can effectively protect the fresh flower from the withering or carbonization under the heating of butane flame. In addition, thermal insulation property was further investigated via infrared camera. As the Ca-BN aerogel monolith $(3.0 \mathrm{~cm}$ thick) was placed on a corundum plate with high temperature, as shown in Fig. S24, a clear temperature gradient through the $\mathrm{Ca}-\mathrm{BN}$ aerogel was observed. As the heating time increases, the top surface of the $\mathrm{Ca}-\mathrm{BN}$ aerogel was maintained a nearly constant temperature at about $102.5^{\circ} \mathrm{C}$ when thickness of $\mathrm{Ca}-\mathrm{BN}$ aerogel was about $3 \mathrm{~cm}$ (Fig. S24).

\subsection{High-Temperature Thermal Stealthy}

The extraordinary high-temperature stability and superior high-temperature heat insulation performance of the Ca-BN aerogel make it useful in high-temperature thermal stealthy [33-36]. According to the Stefan-Boltzmann law: $\mathrm{P}=\varepsilon \sigma \mathrm{T}^{4}$, the thermal radiation of a target is proportional to the surface emittance $(\varepsilon)$ and the fourth power of temperature (T) [33-37]. Thermal stealthy is need to blend targets into their surroundings in infrared imaging to evade infrared thermal detection. For this purpose, various materials and architectures were proposed reducing temperature or regulating IR emissivity of a target and then achieving thermal stealthy, but the realization of thermal stealthy at high temperature up to $1300{ }^{\circ} \mathrm{C}$ in the air still remains a great challenge.

For high-temperature thermal stealthy, superior high-temperature stabilization is necessary. As the $\mathrm{Ca}-\mathrm{BN}$ aerogel was covered on the surface of high-temperature target, IR image of Ca-BN aerogel showed a similar color to the background, and as the thickness of BN aerogel increased, the contrast between aerogel surface and environment decreases and becomes almost consistent (Fig. S25), indicating the radiation temperature of high-temperature target $\left(\sim 1300^{\circ} \mathrm{C}\right)$ was reduced significantly (reduced to about $100^{\circ} \mathrm{C}$ ). However, only relying on the thermal insulation of $\mathrm{Ca}-\mathrm{BN}$ aerogel, the effect of thermal stealthy is limited, as the surface radiation temperature still larger than the background.

Integrating thermal insulation and desired infrared emission in one architecture, which can further reduce the radiation temperature of high-temperature target to around room temperatures, may provide a chance to achieve superior high-temperature thermal stealthy. Aluminum foil possessed a very low infrared emissivity and high infrared reflectance [29, 37-40], and it is usually used in thermal stealthy. However, the aluminum foil will be melted or destroyed in the high temperature above $660{ }^{\circ} \mathrm{C}$ environment and then brought safety problem or become infrared visible (Fig. 4c). Hence, a combination architecture between $\mathrm{Ca}-\mathrm{BN}$ aerogel and aluminum foil was proposed for high-temperature IR stealthy (Fig. S26) [33-36]. As the aluminum foil was covered on the surface of $\mathrm{Ca}-\mathrm{BN}$ aerogel, and they physically stacked with each other, the contract between target and background further decreased (Figs. S25 and S26), promoting the IR invisibility of high-temperature target. Typically, as the butane flame $\left(\sim 1300{ }^{\circ} \mathrm{C}\right.$, Fig. 4 b) was used to heat the target, the combination structure of $\mathrm{Ca}-\mathrm{BN}$ aerogel and aluminum foil was covered on the high-temperature region (Figs. 4d, e and S27), and the high-temperature target become completely infrared invisible (Figs. $4 \mathrm{f}$ and S28), as the radiation temperature detected by infrared camera was about $31 \pm 2{ }^{\circ} \mathrm{C}$, indicating that such Ca-BN aerogel can serve as a promising candidate for high-temperature thermal stealthy [33-36].

\section{Conclusion}

In summary, a Ca-BN aerogel was fabricated through hightemperature treatment of calcium phosphate-doped melamine diborate architecture. This aerogel was constructed by intertwined Ca-BN micro-/nanoribbons, and the Ca element was embedded into the crystal of BN building blocks. Such structure provided an exciting stability, oxidization 
resistance and excellent thermal insulation at high temperature up to $1300{ }^{\circ} \mathrm{C}$ oxidation environment. Typically, this aerogel could resist the burning of butane flame and maintain the megaship very well. Moreover, the Ca-BN aerogel together with $\mathrm{Al}$ foil, via forming a combined structure, can effectively hide high-temperature target (heated by butane flame). The successful doping metal element into crystal structure of BN may be helpful in the future design and fabrication of advanced $\mathrm{BN}$ nanostructures and relevant aerogel materials, and further extend their applications in extreme conditions.

Acknowledgements This work was financially supported by the Royal Society Newton Advanced Fellowship (NA170184), the National Natural Science Foundation of China (52173052) and the Natural Science Foundation of Jiangsu Province (BK20210133).

Funding Open access funding provided by Shanghai Jiao Tong University.

Open Access This article is licensed under a Creative Commons Attribution 4.0 International License, which permits use, sharing, adaptation, distribution and reproduction in any medium or format, as long as you give appropriate credit to the original author(s) and the source, provide a link to the Creative Commons licence, and indicate if changes were made. The images or other third party material in this article are included in the article's Creative Commons licence, unless indicated otherwise in a credit line to the material. If material is not included in the article's Creative Commons licence and your intended use is not permitted by statutory regulation or exceeds the permitted use, you will need to obtain permission directly from the copyright holder. To view a copy of this licence, visit http://creativecommons.org/licenses/by/4.0/.

Supplementary Information The online version contains supplementary material available at https://doi.org/10.1007/ s40820-021-00754-9.

\section{References}

1. J. Pan, J. Wang, Boron nitride aerogels consisting of varied superstructures. Nanoscale Adv. 2, 149-155 (2020). https:// doi.org/10.1039/c9na00702d

2. M. Rousseas, A.P. Goldstein, W. Mickelson, M.A. Worsley, L. Woo et al., Synthesis of highly crystalline $\mathrm{sp}^{2}$-bonded boron nitride aerogels. ACS Nano 7, 8540-8546 (2013). https://doi. org/10.1021/nn402452p

3. X. Xu, Q. Zhang, M. Hao, Y. Hu, Z. Lin et al., Double-negative-index ceramic aerogels for thermal superinsulation. Science 363, 723-727 (2019). https://doi.org/10.1126/science. aav7304
4. H. Cheng, Y. Huang, G. Shi, L. Jiang, L. Qu, Graphene-based functional architectures: Sheets regulation and macrostructure construction toward actuators and power generators. Acc. Chem. Res. 50, 1663-1671 (2017). https://doi.org/10.1021/ acs.accounts. $7 \mathrm{~b} 00131$

5. Z. Li, Z. Liu, H. Sun, C. Gao, Superstructured assembly of nanocarbons: Fullerenes, nanotubes, and graphene. Chem. Rev. 115, 7046-7117 (2015). https://doi.org/10.1021/acs. chemrev.5b00102

6. Z. Liu, L. Ye, J. Xi, J. Wang, Z.-G. Feng, Cyclodextrin polymers: Structure, synthesis, and use as drug carriers. Prog. Poly. Sci. 118, 101408 (2021). https://doi.org/10.1016/j.progpolyms ci. 2021.101408

7. Z.Y. Wu, H.W. Liang, B.C. Hu, S.H. Yu, Emerging carbonnanofiber aerogels: Chemosynthesis versus biosynthesis. Angew. Chem. Int. Ed. 57, 15646-15662 (2018). https://doi. org/10.1002/anie.201802663

8. W. Luo, Y. Wang, E. Hitz, Y. Lin, B. Yang et al., Solution processed boron nitride nanosheets: Synthesis, assemblies and emerging applications. Adv. Funct. Mater. 27, 201701450 (2017). https://doi.org/10.1002/adfm.201701450

9. Q. Weng, X. Wang, X. Wang, Y. Bando, D. Golberg, Functionalized hexagonal boron nitride nanomaterials: Emerging properties and applications. Chem. Soc. Rev. 45, 3989-4012 (2016). https://doi.org/10.1039/c5cs00869g

10. G. Hu, J. Kang, L.W.T. Ng, X. Zhu, R.C.T. Howe et al., Functional inks and printing of two-dimensional materials. Chem. Soc. Rev. 47, 3265-3300 (2018). https://doi.org/10.1039/c8cs0 $0084 \mathrm{k}$

11. J. Shen, Y. Zhu, H. Jiang, C. Li, 2d nanosheets-based novel architectures: synthesis, assembly and applications. Nano Today 11, 483-520 (2016). https://doi.org/10.1016/j.nantod. 2016.07.005

12. Y. Du, X. Zhang, J. Wang, Z. Liu, K. Zhang et al., Reactionspun transparent silica aerogel fibers. ACS Nano 1, 1191911928 (2020). https://doi.org/10.1021/acsnano.0c05016

13. A.C. Pierre, G.M. Pajonk, Chemistry of aerogels and their applications. Chem. Rev. 102, 4243-4266 (2002). https://doi. org/10.1021/cr0101306

14. G. Li, M. Zhu, W. Gong, R. Du, A. Eychmüller et al., Boron nitride aerogels with super-flexibility ranging from liquid nitrogen temperature to $1000{ }^{\circ} \mathrm{C}$. Adv. Funct. Mater. 29, 201900188 (2019). https://doi.org/10.1002/adfm.201900188

15. B. Wang, G. Li, L. Xu, J. Liao, X. Zhang, Nanoporous boron nitride aerogel film and its smart composite with phase change materials. ACS Nano 14, 16590-16599 (2020). https://doi.org/ 10.1021/acsnano.0c05931

16. Y. Xue, P. Dai, M. Zhou, X. Wang, A. Pakdel et al., Multifunctional superelastic foam-like boron nitride nanotubular cellular-network architectures. ACS Nano 11, 558-568 (2017). https://doi.org/10.1021/acsnano.6b06601

17. J. Wang, D. Liu, Q. Li, C. Chen, Z. Chen et al., Lightweight, superelastic yet thermoconductive boron nitride nanocomposite aerogel for thermal energy regulation. ACS Nano 13, 7860-7870 (2019). https://doi.org/10.1021/acsnano.9b02182 
18. J. Lin, X. Yuan, G. Li, Y. Huang, W. Wang et al., Self-assembly of porous boron nitride microfibers into ultralight multifunctional foams of large sizes. ACS Appl. Mater. Interfaces 9, 44732-44739 (2017). https://doi.org/10.1021/acsami.7b161 98

19. Z. Liu, C. Shao, B. Jin, Z. Zhang, Y. Zhao et al., Crosslinking ionic oligomers as conformable precursors to calcium carbonate. Nature 574, 394-398 (2019). https://doi.org/10.1038/ s41586-019-1645-x

20. S. Prasad, A. Gaddam, A. Jana, S. Kant, P.K. Sinha et al., Structure and stability of high $\mathrm{CaO}$ - and $\mathrm{P}_{2} \mathrm{O}_{5}$-containing silicate and borosilicate bioactive glasses. J. Phys. Chem. B 123, 7558-7569 (2019). https://doi.org/10.1021/acs.jpcb.9b02455

21. H. Chen, Z. Yang, Z. Zhang, Z. Chen, M. Chi et al., Construction of a nanoporous highly crystalline hexagonal boron nitride from an amorphous precursor for catalytic dehydrogenation. Ang. Chem. Int. Ed. 58, 10626-10630 (2019). https:// doi.org/10.1002/anie.201904996

22. N.M. Bobkova, N.V. Suprun, Transparent glazes with reduced concentration of $\mathrm{B}_{2} \mathrm{O}_{3}$. Glass Ceram. 53, 362-363 (1996). https://doi.org/10.1007/bf01129672

23. C. Schwarze, A. Gupta, T. Hickel, R. Darvishi Kamachali, Phase-field study of ripening and rearrangement of precipitates under chemomechanical coupling. Phys. Rev. B 95, 174101 (2017)

24. C. Jia, L. Li, Y. Liu, B. Fang, H. Ding et al., Highly compressible and anisotropic lamellar ceramic sponges with superior thermal insulation and acoustic absorption performances. Nat. Commun. 11, 3732 (2020). https://doi.org/10.1038/ s41467-020-17533-6

25. X. Zhang, F. Wang, L. Dou, X. Cheng, Y. Si et al., Ultrastrong, superelastic, and lamellar multiarch structured $\mathrm{ZrO}_{2}-\mathrm{Al}_{2} \mathrm{O}_{3}$ nanofibrous aerogels with high-temperature resistance over 1300 degrees C. ACS Nano 14, 15616-15625 (2020). https:// doi.org/10.1021/acsnano.0c06423

26. R. Menzel, S. Barg, M. Miranda, D.B. Anthony, S.M. Bawaked et al., Joule heating characteristics of emulsion-templated graphene aerogels. Adv. Funct. Mater. 25, 28-35 (2015). https:// doi.org/10.1002/adfm.201401807

27. G. Li, X. Zhang, J. Wang, J. Fang, Correction: From anisotropic graphene aerogels to electron- and photo-driven phase change composites. J. Mater. Chem. A 5, 10722 (2017). https://doi.org/10.1039/c7ta90099f

28. J.F. Poco, J.H. Satcher, L.W. Hrubesh, Synthesis of high porosity, monolithic alumina aerogels. J. Non-Cryst. Solid. 285, 57-64 (2001). https://doi.org/10.1016/s0022-3093(01) 00432-X

29. L. Yuan, X. Weng, W. Du, J. Xie, L. Deng, Optical and magnetic properties of $\mathrm{Al} / \mathrm{Fe}_{3} \mathrm{O}_{4}$ core-shell low infrared emissivity pigments. J. Alloy. Compound. 583, 492-497 (2014). https:// doi.org/10.1016/j.jallcom.2013.08.133
30. H. Jin, X. Zhou, T. Xu, C. Dai, Y. Gu et al., Ultralight and hydrophobic palygorskite-based aerogels with prominent thermal insulation and flame retardancy. ACS Appl. Mater. Interfaces 12, 11815-11824 (2020). https://doi.org/10.1021/ acsami.9b20923

31. W. Fan, X. Zhang, Y. Zhang, Y. Zhang, T. Liu, Lightweight, strong, and super-thermal insulating polyimide composite aerogels under high temperature. Compost. Sci. Technol. 173, 47-52 (2019). https://doi.org/10.1016/j.compscitech.2019.01. 025

32. H. Yang, C. Li, X. Yue, J. Huo, F. Ye et al., New bn/sioc aerogel composites fabricated by the sol-gel method with excellent thermal insulation performance at high temperature. Mater. Design. 185, 108217 (2020). https://doi.org/10.1016/j.matdes. 2019.108217

33. A. Choe, J. Yeom, Y. Kwon, Y. Lee, Y.-E. Shin et al., Stimuliresponsive micro/nanoporous hairy skin for adaptive thermal insulation and infrared camouflage. Mater. Horiz. 7, 32583265 (2020). https://doi.org/10.1039/d0mh01405b

34. J. Lyu, Z. Liu, X. Wu, G. Li, D. Fang et al., Nanofibrous kevlar aerogel films and their phase-change composites for highly efficient infrared stealth. ACS Nano 13, 2236-2245 (2019). https://doi.org/10.1021/acsnano.8b08913

35. H. Zhu, Q. Li, C. Zheng, Y. Hong, Z. Xu et al., High-temperature infrared camouflage with efficient thermal management. Light: Sci Appl (2020). https://doi.org/10.1038/ s41377-020-0300-5

36. L. Li, M. Shi, X. Liu, X. Jin, Y. Cao et al., Ultrathin titanium carbide (mxene) films for high-temperature thermal camouflage. Adv. Funct. Mater. 31, 2103181 (2021). https://doi.org/ 10.1002/adfm.202101381

37. Q. Liao, P. Zhang, H. Yao, H. Cheng, C. Li et al., Reduced graphene oxide-based spectrally selective absorber with an extremely low thermal emittance and high solar absorptance. Adv. Sci. 7, 1903125 (2020)

38. X. Yan, G. Xu, Corrosion and mechanical properties of polyurethane/Al composite coatings with low infrared emissivity. J. Alloy. Compound. 491, 649-653 (2010). https://doi.org/10. 1016/j.jallcom.2009.11.030

39. X. Shi, R. Zhang, K. Ruan, T. Ma, Y. Guo et al., Improvement of thermal conductivities and simulation model for glass fabrics reinforced epoxy laminated composites via introducing hetero-structured BNN-30@BNNS fillers. J. Mater. Sci. Technol. 82, 239-249 (2021). https://doi.org/10.1016/j.jmst. 2021.01.018

40. H. Yan, X. Dai, K. Ruan, S. Zhang, X. Shi et al., Flexible thermally conductive and electrically insulating silicone rubber composite films with BNNS@ $\mathrm{Al}_{2} \mathrm{O}_{3}$ fillers. Adv. Compos. Hybrid Mater. 4, 36-50 (2021). https://doi.org/10.1007/ s42114-021-00208-1 